\title{
Correction to: Review of the accomplishments of mid-latitude Super Dual Auroral Radar Network (SuperDARN) HF radars
}

Nozomu Nishitani ${ }^{1 *}$, John Michael Ruohoniemi², Mark Lester ${ }^{3}$, Joseph Benjamin Harold Baker², Alexandre Vasilyevich Koustov ${ }^{4}$, Simon G. Shepherd ${ }^{5}$, Gareth Chisham ${ }^{6}$, Tomoaki Hori ${ }^{1}$, Evan G. Thomas ${ }^{5}$, Roman A. Makarevich ${ }^{7}$, Aurélie Marchaudon ${ }^{8}$, Pavlo Ponomarenko ${ }^{4}$, James A. Wild ${ }^{9}$, Stephen E. Milan ${ }^{3}$, William A. Bristow ${ }^{7}$, John Devlin ${ }^{10}$, Ethan Miller ${ }^{11}$, Raymond A. Greenwald ${ }^{2}$, Tadahiko Ogawa ${ }^{12}$ and Takashi Kikuchi ${ }^{1}$

Correction to: Prog Earth Planet Sci (2019) 6:27 https://doi.org/10.1186/s40645-019-0270-5

After publication of this article (Nishitani et al. 2019), it was brought to our attention that the figure 5 is incorrect, where the positions of DCE and SPS were misplaced. The correct figure 5 is as below, the original publication has been corrected.

Figure 5:
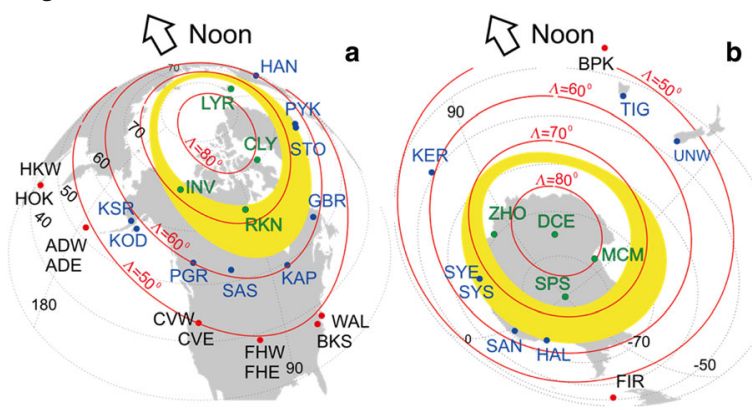

\section{Author details}

'Institute for Space-Earth Environmental Research, Nagoya University, Nagoya 464-8601, Japan. ${ }^{2}$ Virginia Tech Department of Electrical and Computer Engineering, Blacksburg, VA, USA. ${ }^{3}$ University of Leicester, Leicester, UK. ${ }^{4}$ University of Saskatchewan, Saskatoon, SK, Canada. ${ }^{5}$ Thayer School of Engineering, Dartmouth College, Hanover, NH, USA. ${ }^{6}$ British Antarctic Survey, Cambridge, UK. ${ }^{7}$ University of Alaska Fairbanks, Fairbanks, AK, USA. ${ }^{8}$ Institut de Recherche en Astrophysique et Planétologie, University of Toulouse, CNRS, CNES, Toulouse, France. ${ }^{9}$ Lancaster University, Lancaster, UK. ${ }^{10} \mathrm{La}$

* Correspondence: nisitani@isee.nagoya-u.ac.jp

The original article can be found online at https://doi.org/10.1186/s40645-01 9-0270-5

${ }^{1}$ Institute for Space-Earth Environmental Research, Nagoya University, Nagoya 464-8601, Japan

Full list of author information is available at the end of the article
Trobe University, Melbourne, Australia. ${ }^{11}$ Applied Physics Laboratory, Johns Hopkins University, Baltimore, MD, USA. ${ }^{12}$ National Institute of Information and Communications Technology, Tokyo, Japan.

Received: 12 July 2019 Accepted: 12 July 2019 Published online: 30 July 2019

\section{Reference}

Nishitani N et al (2019) Review of the accomplishments of mid-latitude Super Dual Auroral Radar Network (SuperDARN) HF radars. Prog Earth Planet Sci 6: 27 https://doi.org/10.1186/s40645-019-0270-5 